\title{
CASA REVISTA: ARQUITETURA DE FONTE ABERTA
}

\author{
HOUSE MAGAZINE: OPEN SOURCE ARCHITECTURE
}

\section{Andrés Passaro' ; Clarice Rohde}

RESUMO: A popularização das novas tecnologias de fabricação digital vêm alterando os modos de produção da sociedade contemporânea. O compartilhamento aberto de informações, dentro de uma nova lógica produtiva, tem o potencial de mudar o sistema econômico vigente. e de até transformar os rumos da globalização em curso. O presente trabalho aborda um novo sistema construtivo de fonte aberta que utiliza a fabricação digital na produção de habitações de baixo custo. O projeto Casa Revista, desenvolvido no laboratório LAMO3D da FAU-UFRJ, tem como objetivo alimentar a renovação da produção independente de habitações, inserindo uma nova tecnologia construtiva no vocabulário popular e explorando seus potenciais. Baseado no sistema WikiHouse de construção, o projeto alia conhecimento global à produção local, tropicalizando o seu conteúdo. A experiência contou com a prototipagem em escala real de um primeiro modelo, usinado e montado por estudantes da graduação, a fim de testar a qualidade do sistema e sua viabilidade técnica de implementação como tecnologia social. O projeto mostrou-se intuitivo, de complexidade simples e rico em possibilidades de manipulação e aperfeiçoamento. São os projetos e tecnologias de fonte aberta que vêm promovendo o alargamento de usos do conhecimento por novos atores, gerando uma dispersão da produção. Cabe a nós arquitetos reconhecermos esse potencial e moldar suas infinitas possibilidades de aplicação.

PALAVRAS-CHAVE: Fonte Aberta; WikiHouse; Fabricação Digital; CNC; Habitação Social.

ABSTRACT: The popularization of new digital fabrication technologies is changing the production practices in contemporary society. The open sharing of information within a new logic of production, has the potential to change the current economic system, and even change the course of the ongoing globalization process. This paper discusses a new open source building system that uses digital manufacturing in the production of low-cost housing. The project House Magazine, developed in LAMO3D laboratory at FAU-UFRJ, aims to feed the renewal of the production of independent houses, inserting a new construction technology in the popular vocabulary and exploring their potential. Based on WikiHouse system, the project combines global knowledge to local production, tropicalizing its content. The project has reached its first prototype in real scale, milled and assembled by graduate students in order to test the quality of the system and its technical feasibility of implementation as social technology. The project proved to be intuitive, of simple complexity and rich in possibilities of manipulation and improvement. Open projects and open source technologies are promoting the extension of uses of the knowledge by new players, generating a dispersion of production. It is up to us architects to recognize this potential and shape its endless application possibilities.

KEYWORDS: Open Source; WikiHouse; Digital Fabrication; CNC; Social Housing. Federal do Rio de Janeiro - UFRJ 


\section{INTRODUÇÃO}

A fabricação digital está cada vez mais presente na vida contemporânea e vem se popularizando, tendo em vista a crescente abertura de FabLabs ${ }^{1}$, os laboratórios de fabricação digital. Muitos inclusive, com foco no público infantil, oferecendo cursos de programação e robótica, como o OLABI Makerspace $^{2}$ no Rio de Janeiro e a rede FabLAb Livre SP em São Paulo ${ }^{3}$. Estes espaços tem papel fundamental na formação de uma nova geração de makers, pessoas capazes de se apropriar das tecnologias através do conhecimento compartilhado. O maquinário e os processos construtivos já não são de uso exclusivo da indústria, estando presente nesses laboratórios, e até mesmo à venda em livrarias de uma grande rede brasileira, como a impressora 3D Cube ${ }^{4}$, tornando-se objetos de consumo do público em geral.

A sociedade independente vem ganhando expressão, beneficiando-se da crescente disponibilidade de softwares e hardwares livres, a tecnologia de fonte aberta ${ }^{5}$. Desde o advento da internet em 1991, com intuito de facilitar o compartilhamento de dados e o trabalho colaborativo, a quantidade de informações disponíveis na rede só aumenta. É possível encontrar tutoriais dos mais diversos, compartilhando conhecimentos e até projetos para construção, desde móveis, casas, até máquinas industriais necessárias para a construção da vida contemporânea, como as desenvolvidas pelo grupo Open Source Ecology ${ }^{6}$. O conhecimento está cada vez mais acessível através desses projetos abertos, disponíveis gratuitamente na rede. Se a tirania da informação e do dinheiro é atribuída por Milton Santos (2000) como o pilar da desigualdade social da globalização atual, é a tecnologia de fonte aberta que vem democratizar o acesso à informação e às ferramentas para a construção de uma nova globalização.

Enquanto a sociedade se encontra em meio a um ensaio de um futuro próximo, os laboratórios mais avançados do mundo prototipam possibilidades de aplicação das novas tecnologias de fabricação, experimentando esse futuro na prática. O pioneiro no uso de robôs na arquitetura ETH Zurich ${ }^{7}$ apresentou, em 2006, The Programmed Wall, a primeira parede de tijolo criada através de algoritmos processados por computador e construída por um robô na história das civilizações (Gramazio e Kohler, 2014). Em 2012, o projeto In Situ Robotic Fabrication ensaiou o uso de braços robóticos no canteiro de obras, com capacidades adaptativas para se localizar no espaço e aos demais objetos, processando variações de material e interagindo com o homem (Gramazio e Kohler, 2014). Outro projeto intitulado Minibuilders, desenvolvido no IAAC $^{8}$, aplica robótica e processos aditivos de impressão 3D à construção arquitetônica, buscando atualizar a prática construtiva em relação às novas tecnologias já muito desenvolvida em outras áreas da indústria (Nan, 2015). É no meio acadêmico, através do ensino e da pesquisa de novas práticas projetuais, que se encontra o estímulo para uma futura atualização da indústria e das práticas da construção civil, ainda muito precárias no Brasil.

${ }^{1}$ Os Fab Labs fazem parte de uma rede mundial de laboratórios de fabricação digital com o objetivo de estimular a criatividade, inovação e a prototipagem de ideias, através do acesso a equipamentos e conhecimento. A rede Fab Lab surgiu em 2001 no MIT, e para fazer parte é preciso atender a demandas mínimas estabelecidas no Fab Charter. O surgimento desses laboratórios no munto tem tido crescimento exponencial, e no Brasil eles estão conectados através da rede FabLAb Brasil. http://www.fablabbrasil.org

O Olabi é uma empresa social focada em estimular a aprendizagem de novas tecnologias e estimular a inovação social. Seu makerspace é voltado para a experimentação, onde pessoas compartilham ferramentas, máquinas e conhecimentos. http://olabi.co

A cidade de São Paulo é a primeira do mundo a ter uma rede pública de laboratórios de fabricação, em sua maioria localizados em áreas periféricas. http://fablablivresp.art.br/

${ }^{4} \mathrm{http}: / /$ www.saraiva.com.br/impressora-3d-cube-3-cinza-9184062.html

${ }^{5} \mathrm{~A}$ iniciativa de fonte aberta (open source initiative) teve início na área de desenvolvimento e compartilhamento de softwares de forma aberta, consolidando-se através de licenças de uso aplicáveis a qualquer tipo de informação. http://opensource.org

${ }^{6}$ A meta do grupo Open Source Ecology é estimular uma "economia de fonte aberta" na qual a colaboração livre estimula a inovação por novos atores. http://opensourceecology.org

O Instituto Federal de Tecnologia de Zurique (ETH Zurich) emprega tecnologias de ponta em suas pesquisas como as desenvolvidas pelo grupo Gramazio Kohler Research http://gramaziokohler.arch.ethz. $\mathrm{ch} /$

${ }^{8}$ Instituto de Arquitetura Avançada da Catalunha (IAAC) https://iaac.net/ 


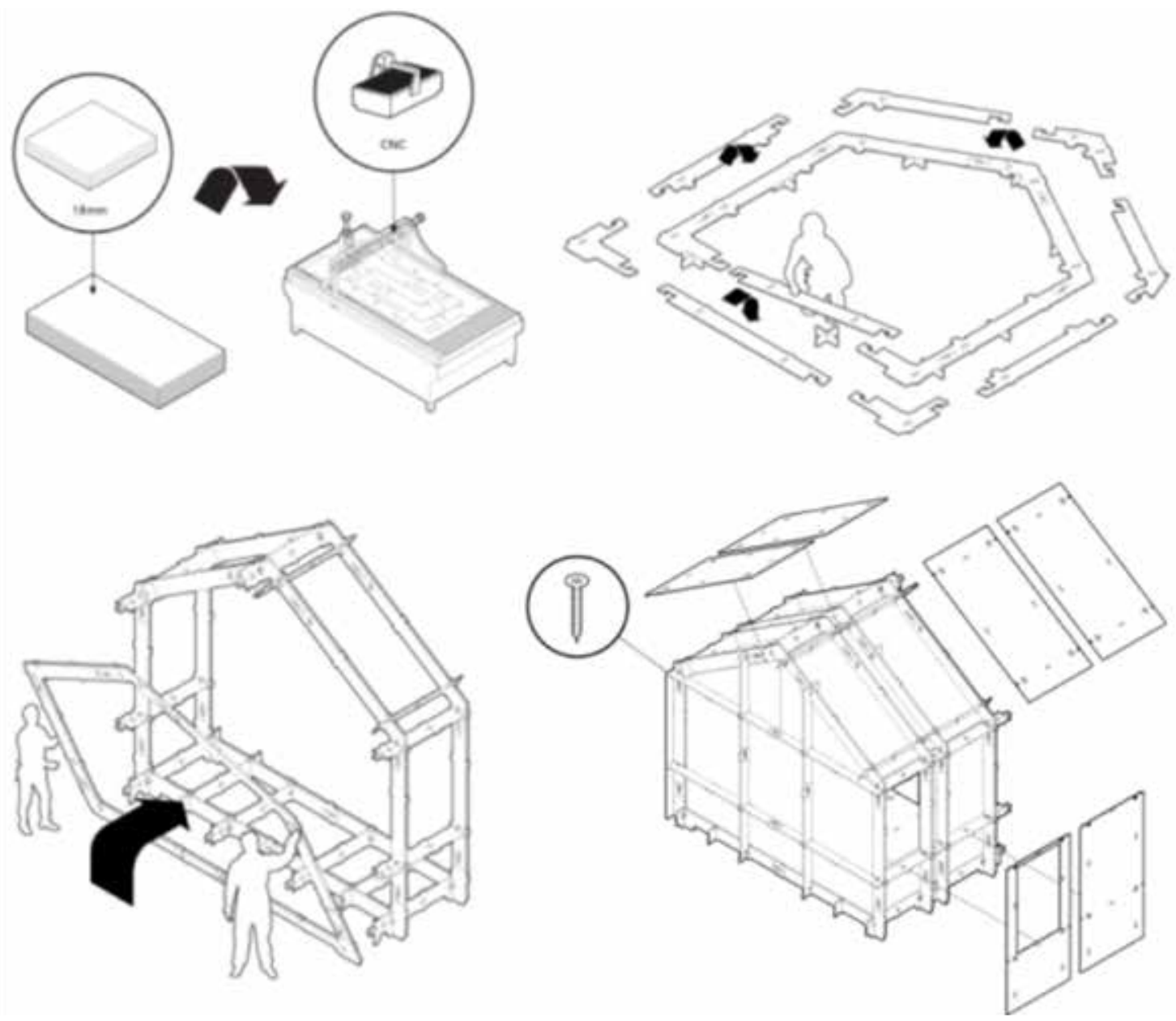

O LAMO3D ${ }^{9}$ tem seus estudos direcionados a esse debate. Estabelecido como grupo de pesquisa em 2013, o Laboratório coordenado pelo Prof. Dr. Andrés Passaro vem promovendo uma série de workshops, oficinas e palestras, provocando uma mudança de perspectiva dentro da escola.

O projeto Casa Revista, desenvolvido no laboratório, tem como objetivo propor uma atualização da produção independente de habitações, inserindo uma nova tecnologia construtiva e explorando seus potenciais. Baseado no sistema WikiHouse ${ }^{10}$ desenvolvido em Londres e de fonte aberta (Fig 1), o estudo busca seu abrasileiramento, sua aclimatação e a solução de questões básicas que envolvem o morar. Para tal, foi construído um primeiro protótipo em escala real, a primeira WikiHouse da América Latina (Fig 2). Conseguimos assim atestar a sua aplicação prática como solução de moradia rápida e barata, aperfeiçoando a técnica e sua adaptação às condições locais. Com o intuito de renovar o debate sobre a produção habitacional no Brasil, o projeto Casa Revista propõe a aplicação de novas tecnologias de fabricação à produção de habitação de forma autônoma e colaborativa. Baseado no empoderamento do morador-construtor, este se torna apto a construir sua própria casa através do uso intuitivo de novas tecnologias que aos poucos vão se consolidando através da cultura colaborativa de fonte aberta.

${ }^{9}$ LAMO3D - Laboratório de Modelos 3D e Fabricação Digital da Faculdade de Arquitetura e Urbanismo da UFRJ.

${ }^{10} \mathrm{O}$ grupo WikiHouse é um dos pioneiros na aplicação de tecnologias de fabricação digital na concepção e produção de casas, estudando os impactos que a Quarta Revolução Industrial (a da informação ou data) traz à economia e à organização social. http://www.wikihouse.cc/ 


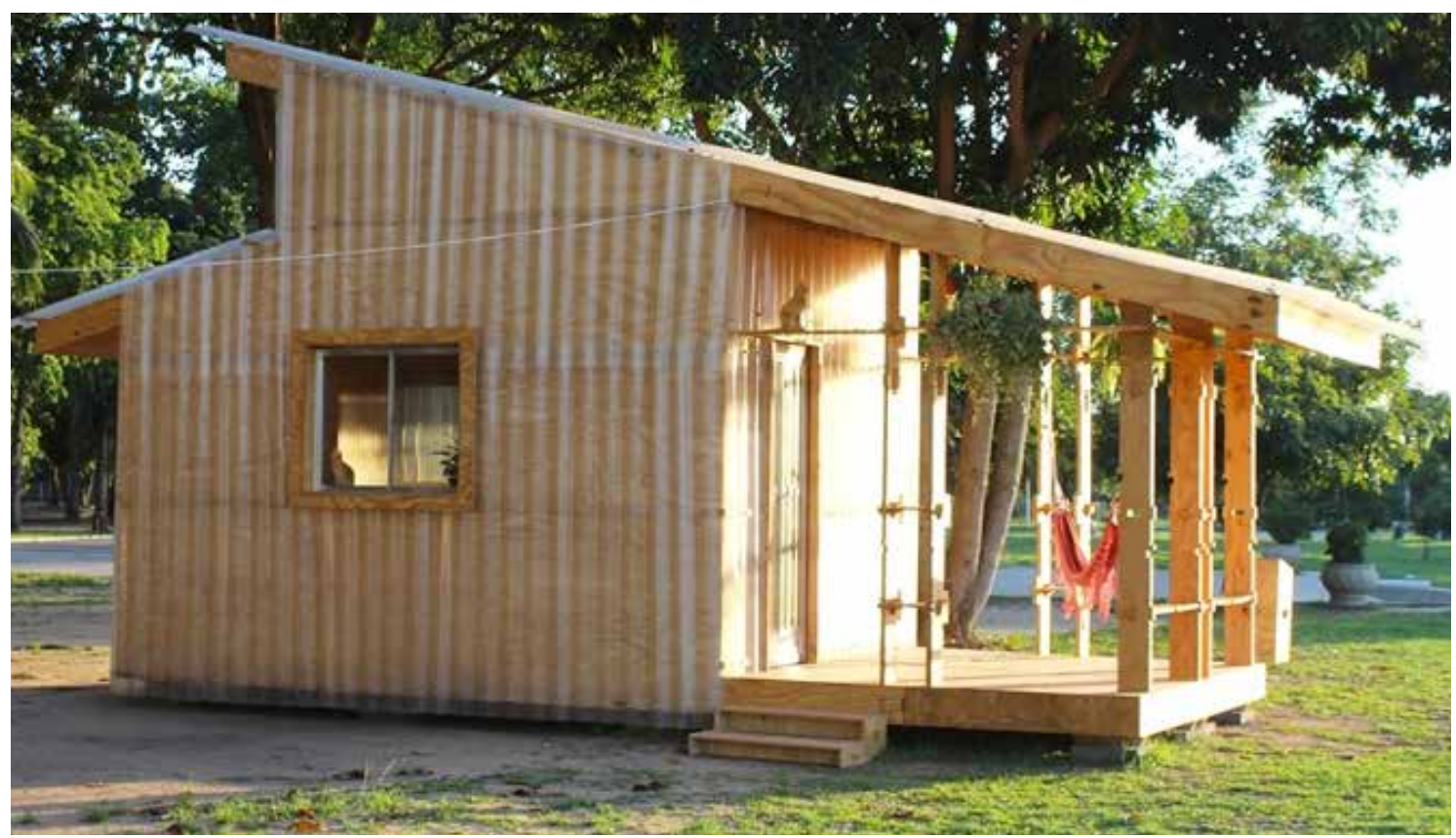

Figura 2: Casa Revista construída pelo LAMO3D. Acervo dos autores.
O projeto da casa, de livre acesso, pode ser produzido em qualquer oficina de fabricação digital, ou FabLab, equipado com uma router $\mathrm{CNC}^{11}$, e então montado tendo como guia um manual de montagem, tão simples quanto um jogo de montar.

O presente trabalho trata, através da própria experiência construtiva, da possível aplicação das novas tecnologias de fabricação de forma independente e autônoma, como ferramenta acessível à maior parte da população em um futuro próximo. Assumindo as ideias de Milton Santos (1994: p.20),“Ciência, tecnologia e informação são a base técnica da vida social atual - e desse modo devem participar das construções epistemológicas renovadoras das disciplinas históricas. Mas não podemos esquecer de que vivemos em um mundo extremamente hierarquizado", percebe-se o potencial do conhecimento de fonte aberta e livre na geração de transformações mais profundas na ordem social, introduzindo à cena global novos atores.

\section{METODOLOGIA}

O projeto nasceu de experimentações realizadas com o sistema WikiHouse de construção. O grupo possui uma plataforma open source colaborativa, disponibilizando na rede todos os projetos desenvolvidos, construídos ou não. Por ser de fonte aberta, o sistema apresenta um rápido crescimento e evolução, com colaboradores no mundo todo, aliando produção local e conhecimento global.

"O sistema funciona com pórticos formados por peças de madeira compensada em chapas cortadas em uma fresadora CNC. As peças do pórtico são unidas por uma junção em 'S', e o pórtico duplicado com o sentido do 'S' invertido para garantir rigidez à junção. Os travamentos entre pórticos são feitos com peças transversais que se cruzam por orifícios nos pórticos e são fixadas com cunhas.

${ }^{11}$ As máquinas de Controle Numérico Computadorizado (CNC) são capazes de produzir objetos físicos a partir de um projeto digital convertido em código numérico para manufatura, baseado em coordenadas espaciais. 
Esse sistema trava a estrutura nas três direções sem fazer uso de parafusos, apenas com encaixes de peças de madeira compensada. Tem-se o esqueleto da estrutura que é contraventado com a fixação de chapas de fechamento que se encaixam em abas da estrutura.” (Passaro e Rohde, 2014)

A Casa Revista foi desenvolvida como projeto de conclusão de curso de graduação pela arquiteta Clarice Rohde, orientado pelos professores Andrés Passaro e Marcos Silvoso. A execução do projeto foi realizada pelo LAMO3D em duas oficinas abertas, o LAMO Summer Camp, oficina de fabricação digital, e a Construção da Casa Revista, ambas realizadas no verão de 2015, em parceria com o Laboratório de Ensino de Materiais de Construção e Estudo do Solo - LEMC, coordenado pelo Prof. Dr. Marcos Martinez Silvoso.

A metodologia de projeto foi apresentada de forma aprofundada em artigo anterior, publicado nos anais do Seminário Habitar 2014 (Passaro e Rohde, 2014). Nele são descritos os procedimentos adotados na definição dos perfis da estrutura, o espaçamento entre os pórticos, sua adaptação ao clima tropical úmido e as possibilidades de personalização do projeto a partir de uma mesma base de peças (Fig 3).

Figure 3: Possibilidade de diferentes tipologias do pórtico estrutural a partir do intercâmbio de peças estratégicas. Acervo dos autores.

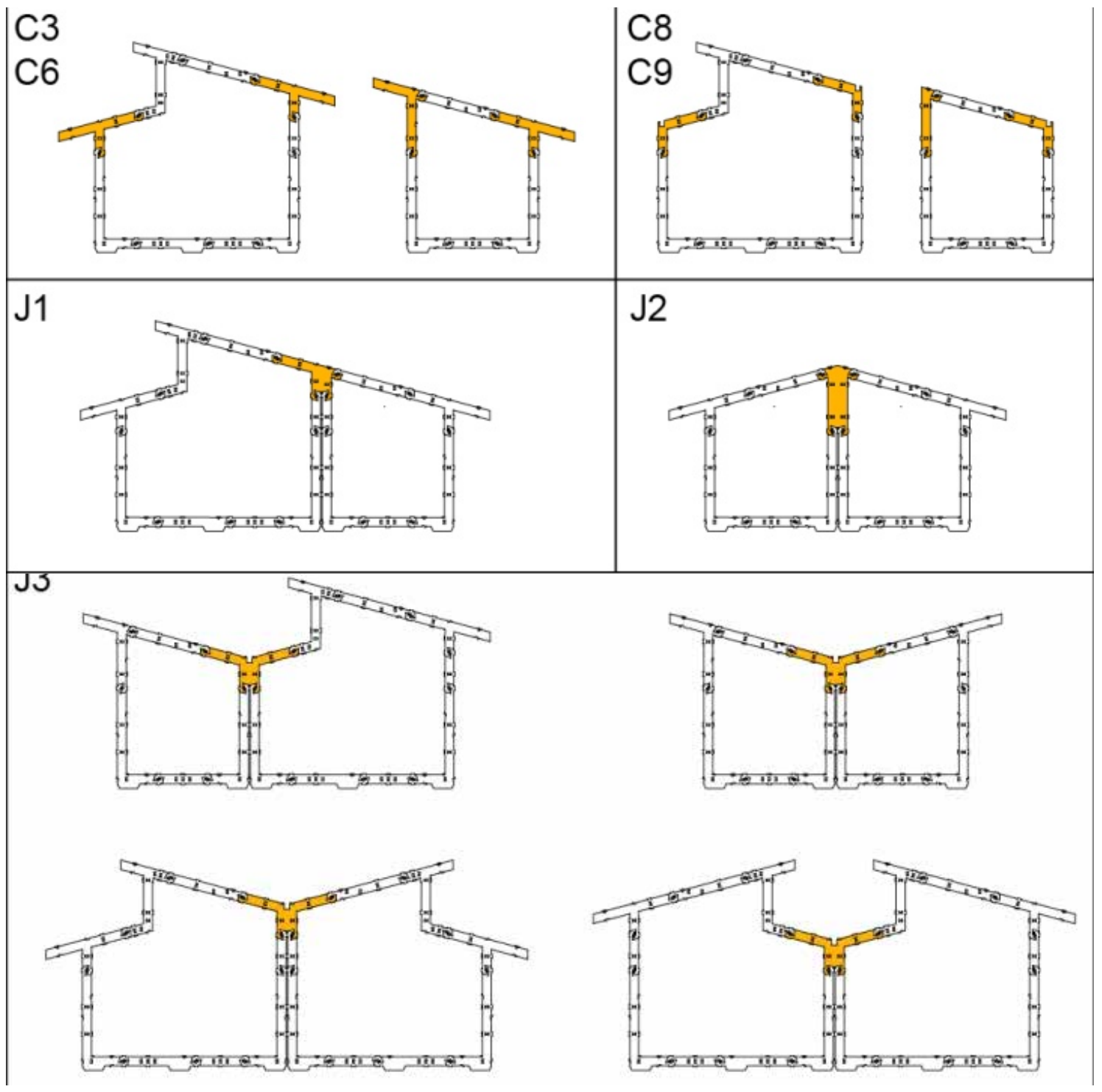


Trata-se de uma proposta de arquitetura de banca de jornal, uma revista com periodicidade e diversidade que traz projetos variados que partem de um mesmo catálogo de peças para atingir diversas configurações espaciais. $\mathrm{O}$ intuito é atender a distintas demandas e estimular a personalização do projeto por parte do leitor-construtor. Na revista, encontram-se não só o projeto e o manual de montagem, mas também instruções para implantação de sistemas complementares de reuso de águas e captação de energia solar, assim como instruções para melhor implantar a habitação de acordo com o terreno, ventos e insolação. O formato de revista visa atingir a população mais necessitada de conhecimento para a autoconstrução de sua moradia, buscando a popularização das tecnologias de fabricação digital.

Após a fase inicial de compreensão do funcionamento do sistema construtivo, deu-se início à fase de adaptações às demandas projetuais. Utilizandosimulaçõesemsoftwaresemodelosfísicosemescala,foramdefinidos os perfis dos pórticos a serem utilizados e os espaçamentos entre eles (Fig 4).

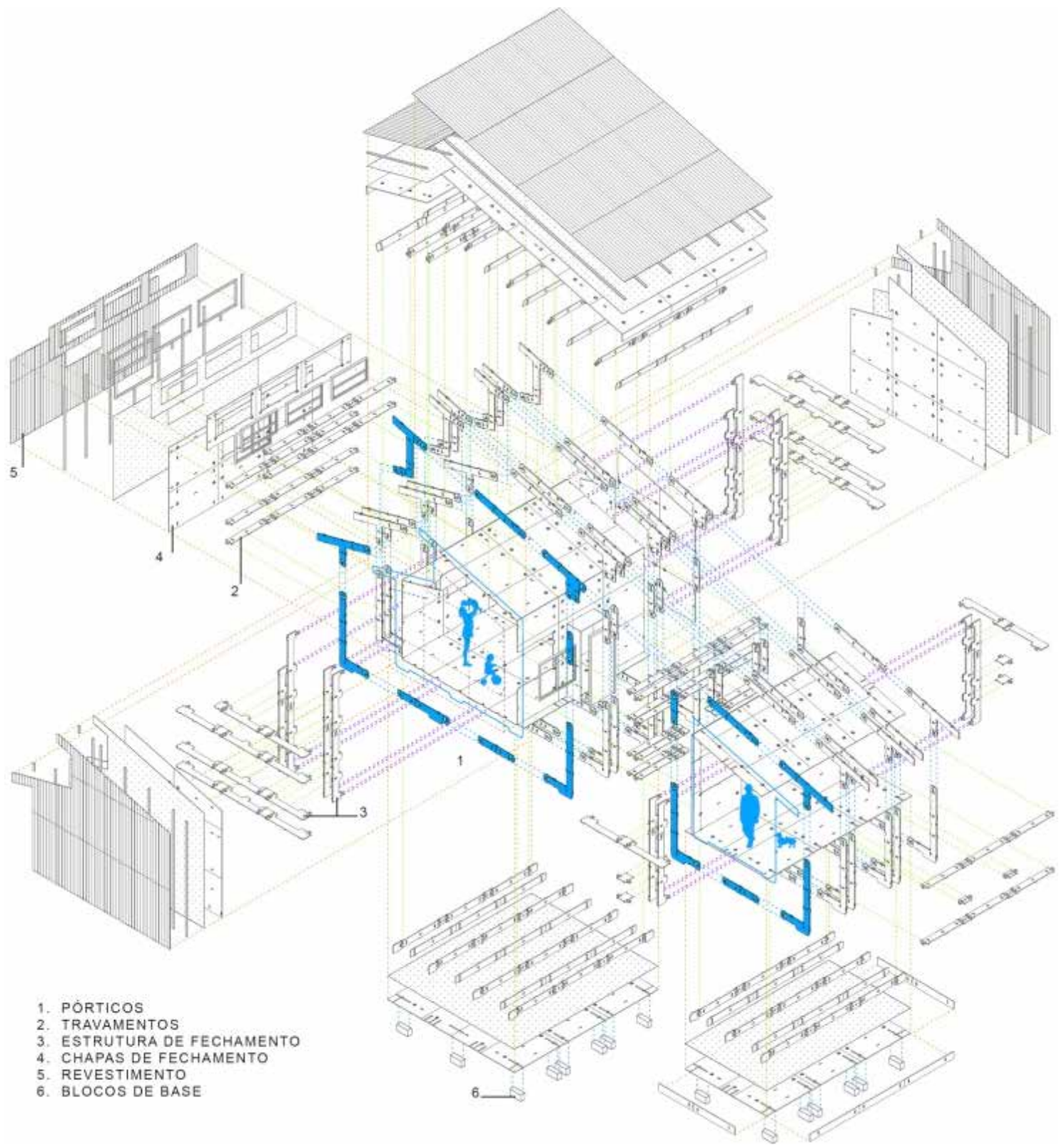


A adoção de duas alturas permite a recombinação entre pórticos para atingir diversas tipologias, assim o projeto é expansível tanto através da repetição de pórticos longitudinalmente como através da associação lateral entre eles.

Para atingir essa liberdade compositiva, o mesmo ritmo estrutural foi adotado em ambos os sentidos, através do casamento entre demandas como vão de esquadrias, dimensão da estrutura e espaçamento para passagem de tubulações. Essas definições, bem como a otimização de peças só foram possíveis através de um contínuo exercício de prototipagem rápida utilizando corte a laser, por meio do qual diversas possibilidades foram testadas.

Além do estudo, domínio e manipulação da técnica, o projeto apreendeu os aspectos da cultura popular brasileira do morar, identificados como de caráter múltiplo por se tratar de uma nação mestiça, lavada com sangue de índio, negro e tropical (Ribeiro, 1990). O reconhecimento de elementos de sua cultura material, identificados como tipicamente brasileiros, demonstrou ser o caminho para uma primeira aproximação entre o povo brasileiro e as tecnologias de fabricação digital, alcançando uma ótima receptividade, além da qualidade ambiental.

O telhado em duas águas, iconográfico, ganhou um desencontro entre as águas para abrigar janelas que ventilam e retiram a massa de ar quente do ambiente, adaptando a estrutura ao clima e cor local. O beiral, consagrado na arquitetura popular, é incorporado no vocabulário da arquitetura digital, representando sua produção tropicalizada. A varanda, presente na maioria das casas brasileiras, não poderia faltar como elemento regulador térmico e de bem-estar, onde se pendura rede e coloca vaso de planta.

Buscou-se evitar uma visão romântica que delimita a cultura popular entre o primitivismo, o purismo e o comunitarismo, tendo como perspectiva:

“... a cultura popular como expressão dos dominados, buscando a forma pelas quais a cultura dominante é aceita, interiorizada, reproduzida e transformada, tanto quanto as formas pelas quais é recusada, negada e afastada, implícita ou explicitamente, pelos dominados. (...) Por esses motivos, não trataremos a cultura popular, no Brasil, pelo prisma de uma totalidade que se põe como antagônica à totalidade dominante, mas como um conjunto disperso de práticas, representações e formas de consciência que possuem lógica própria distinguindo-se da cultura dominante exatamente por essa lógica de práticas, representações e formas de consciência.” (Chaui, 2014, p.28)

Sob essa ótica, percebe-se a importância do conhecimento de fonte aberta acessível à população, que a partir do seu domínio é capaz de transformá-lo e ressignificá-lo através de lógicas próprias e não hierarquizadas. A arquitetura de fonte aberta aqui apresentada incorpora elementos da cultura popular justamente para tornar possível sua ressignificação pelo usuário.

Esse estudo trata de uma especulação acerca do futuro, quando, não muito distante daqui, teremos as tecnologias de fabricação digital popularizadas e acessíveis em formato aberto. A população que por tanto tempo foi mantida como massa passiva manipulável aos interesses do grande capital, vai enfim se tornar ativa de forma independente e múltipla, quando ocorrer uma dispersão do poder de produção. São os projetos e tecnologias de fonte aberta que promovem o alargamento de usos do conhecimento e dos avanços tecnológicos, e cabe a nós arquitetos reconhecer esse potencial e alimentá-lo com infinitas possibilidades de aplicação.
Figure 4: Perspectiva do projeto mostrando as peças do sistema. Acervo dos autores. 


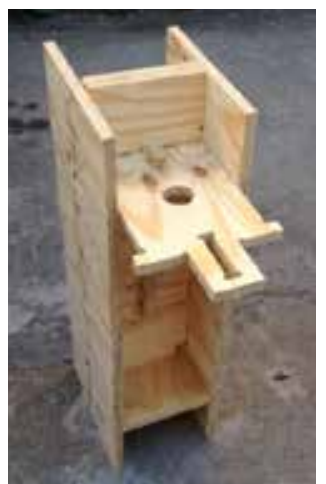

Figura 5: Primeira seção produzida para verificação dos encaixes. Acervo dos autores.

Figura 6: Capacitação dos alunos na operação do maquinário. Acervo dos autores.

Figura 7: Detalhe da junção em S. Acervo dos autores.

\section{LAMO Summer Camp}

Para colocar à prova o sistema construtivo e suas lógicas de aplicação chegamos à fase de prototipagem em escala real. O LAMO Summer Camp foi o primeiro acampamento de verão promovido pelo LAMO3D, oferecendo a oportunidade de expandir a experiência de fabricação digital aos estudantes de arquitetura da UFRJ. Com o laboratório equipado desde 2013 com impressoras 3D e máquina de corte a laser, foi necessário recorrer a uma parceria com empresa do ramo que nos cedeu o espaço e a máquina router CNC para a realização dos cortes. Durante os meses de janeiro e fevereiro de 2015 foram usinadas 200 chapas de madeira compensada por cerca de 15 alunos.

No primeiro contato com o maquinário foi produzida uma seção em que todos os tipos de encaixe utilizados no projeto estavam presentes. Com a verificação de que os encaixes estavam funcionando milimetricamente, deu-se início à produção do primeiro pórtico da estrutura enquanto fazia-se a capacitação dos estudantes na geração de desenhos, códigos e operação da máquina (5, 6 e 7).
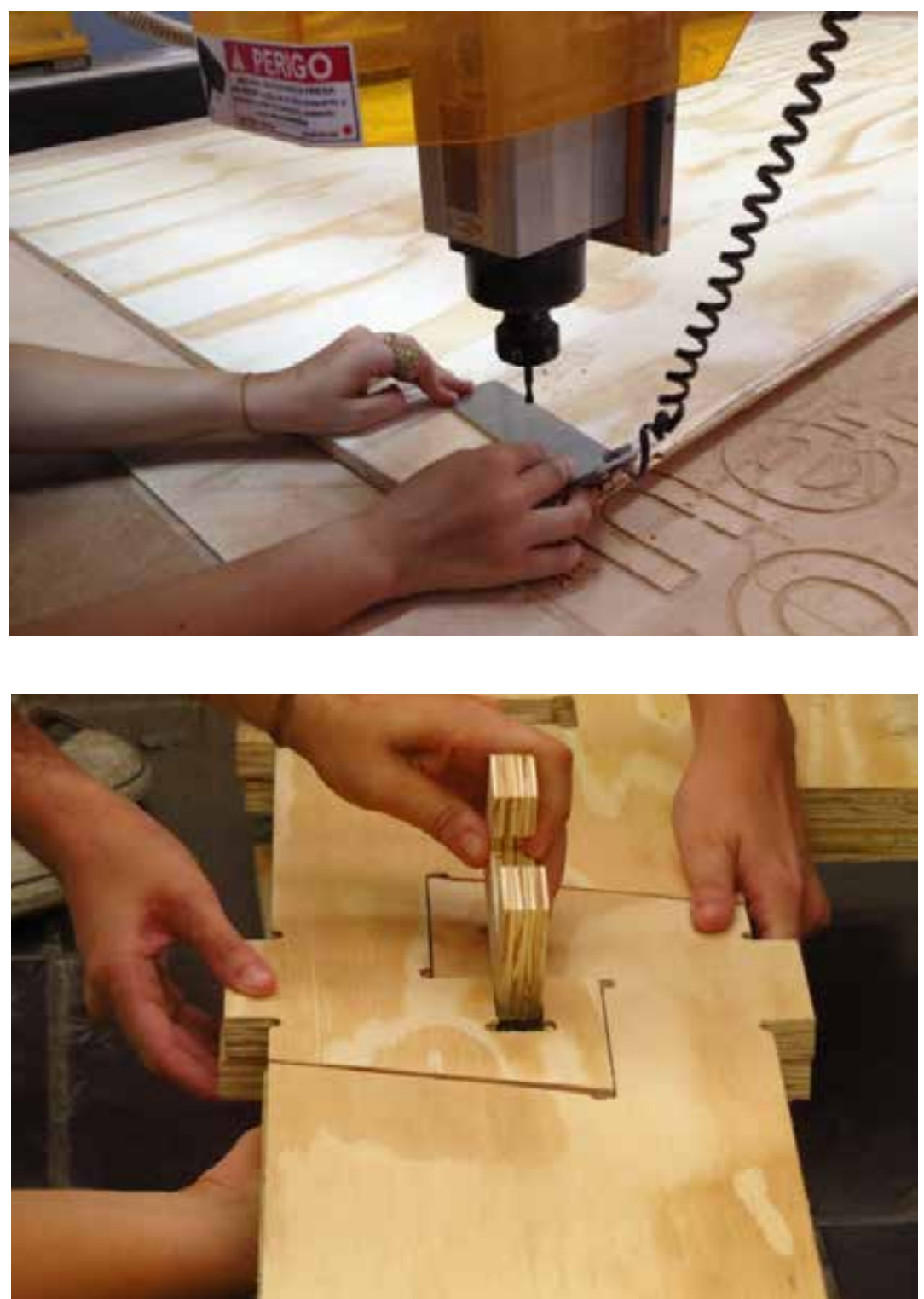


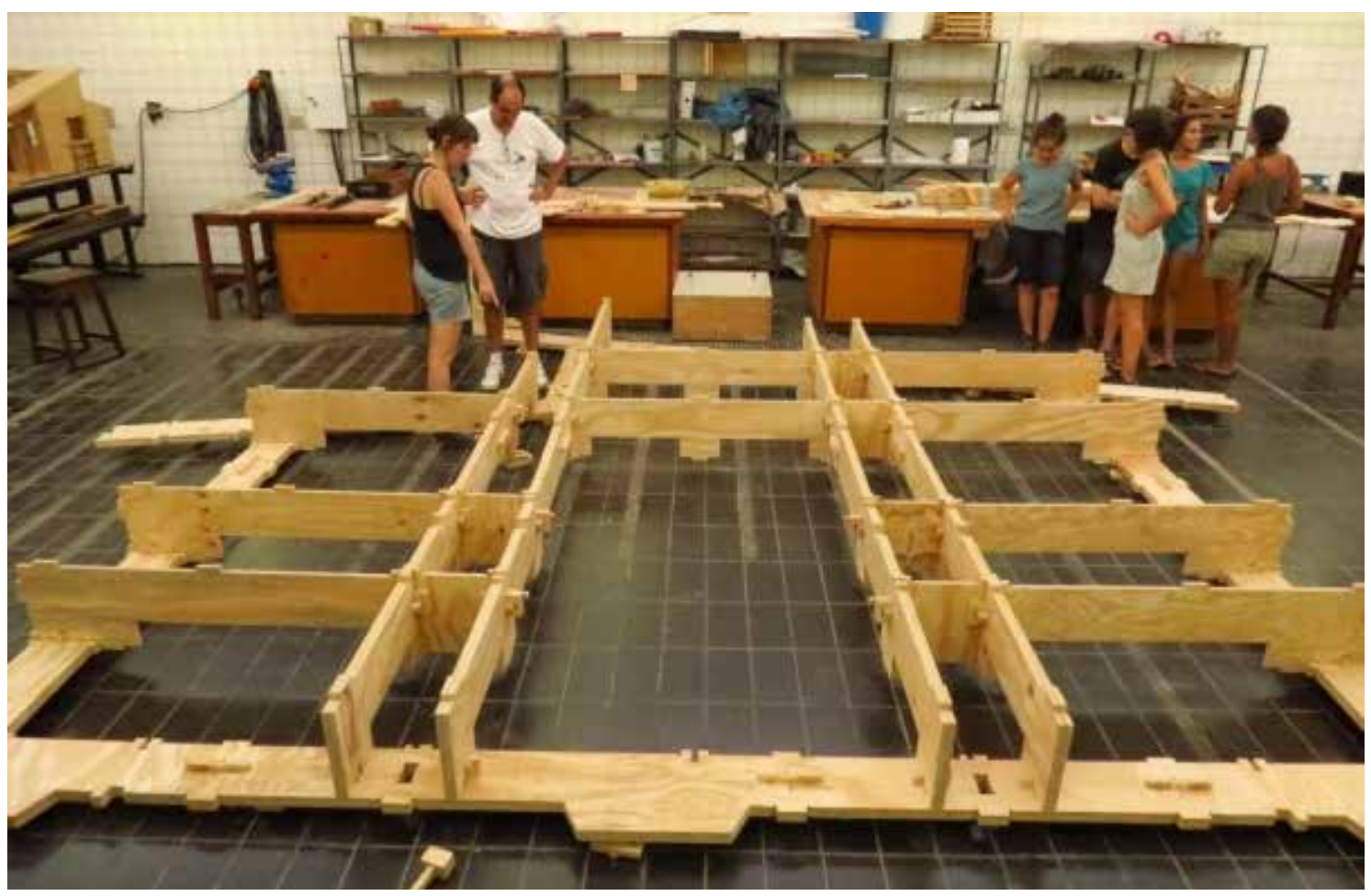

O primeiro pórtico da estrutura foi montado no laboratório, como teste e ensaio para a montagem final (Fig 8). Apenas uma peça na estrutura de fechamento apresentou problemas na montagem e precisou ser redesenhada, por não comportar dois eixos de encaixe simultâneo. Com o ensaio, definiu-se a ordem de montagem do sistema, e que apenas o pórtico maior seria pré-montado e erguido, acoplando o perfil menor, da varanda, na medida em que a estrutura já estivesse de pé e estável.

A produção das peças seu deu na ordem: pórticos (série A, série B), travamentos, estrutura de fechamento final e chapas de fechamento, a mesma ordem aplicada à montagem (9). Posteriormente, realizou-se o corte do mobiliário desenhado pela equipe do LAMO3D, alguns inspirados em desenhos abertos disponíveis na internet.

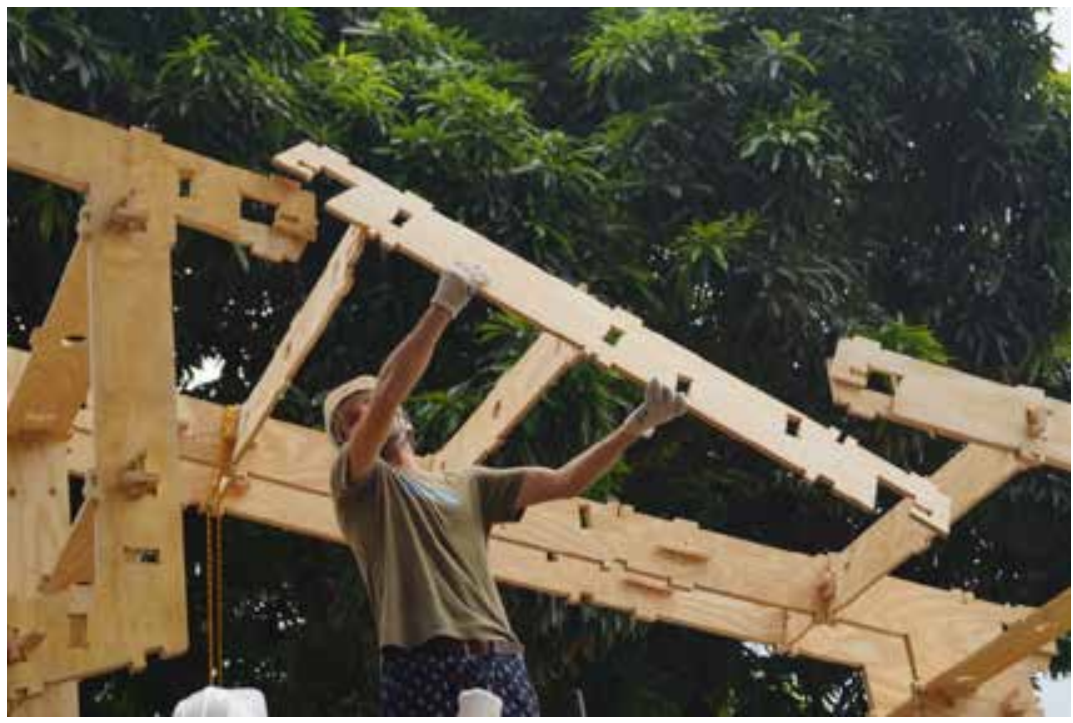

Figura 8: Detalhe da junção em S. Acervo dos autores.
Figura 9: Detalhe do encaixe das peças do pórtico contendo série $A$ e série $B$. Acervo dos autores. 


\section{Construção da Casa Revista}

Com as peças lixadas e envernizadas, deu-se início à oficina de construção da Casa Revista, com a participação de 50 voluntários, entre estudantes, professores e funcionários do laboratório. Foi o primeiro contato com o sistema para a maioria, que após uma rápida apresentação de seu funcionamento, passou para a compreensão dos desenhos do manual de montagem e produção das primeiras estruturas no solo, o que permitiu constatar a facilidade de montagem do sistema (Fig 10, 11 e 12).

Ao longo da primeira semana foi feita a locação dos blocos de base, a montagem da estrutura composta por pórticos, travamentos e estrutura de fechamento final, e iniciou-se a colocação das chapas de fechamento. Na segunda semana foram feitas as instalações elétricas com a finalização dos fechamentos, e a colocação do revestimento final em telha plástica e as esquadrias.

Este primeiro protótipo de habitação foi montado nos jardins em frente à Faculdade de Arquitetura e Urbanismo da UFRJ, com sua varanda voltada para o norte, de modo que o alpendre protegesse a habitação da maior insolação. Os blocos de base utilizados $(40 \times 40 \times 10 \mathrm{~cm})$ são de concreto permeável, assentados sobre saibro para uma correção ligeira de nível. Dentre os quatro pórticos que constituem o modelo, optamos por começar pelos dois centrais, espaçados por travamentos de apenas $30 \mathrm{~cm}$, e que por isso apresentavam maior estabilidade. Postos de pé e escorados com madeira, passamos para o encaixe dos travamentos maiores, de $120 \mathrm{~cm}$ que comportam as aberturas de esquadria do sistema.

O passo seguinte precisou ser repensado, pois a tentativa de acoplamento do pórtico subsequente acrescido da estrutura de fechamento final se mostrou falha. Além de pesada, a estrutura precisava encaixar simultaneamente em 18 pontos, e os travamentos longos, de $120 \mathrm{~cm}$, se encontravam desalinhados pela força do peso próprio. Optamos por simplificar a montagem, construindo o pórtico seguinte peça por peça. Começando pelos pés, cada peça nova

Figura 10: Organização das peças da estrutura. Acervo dos autores.

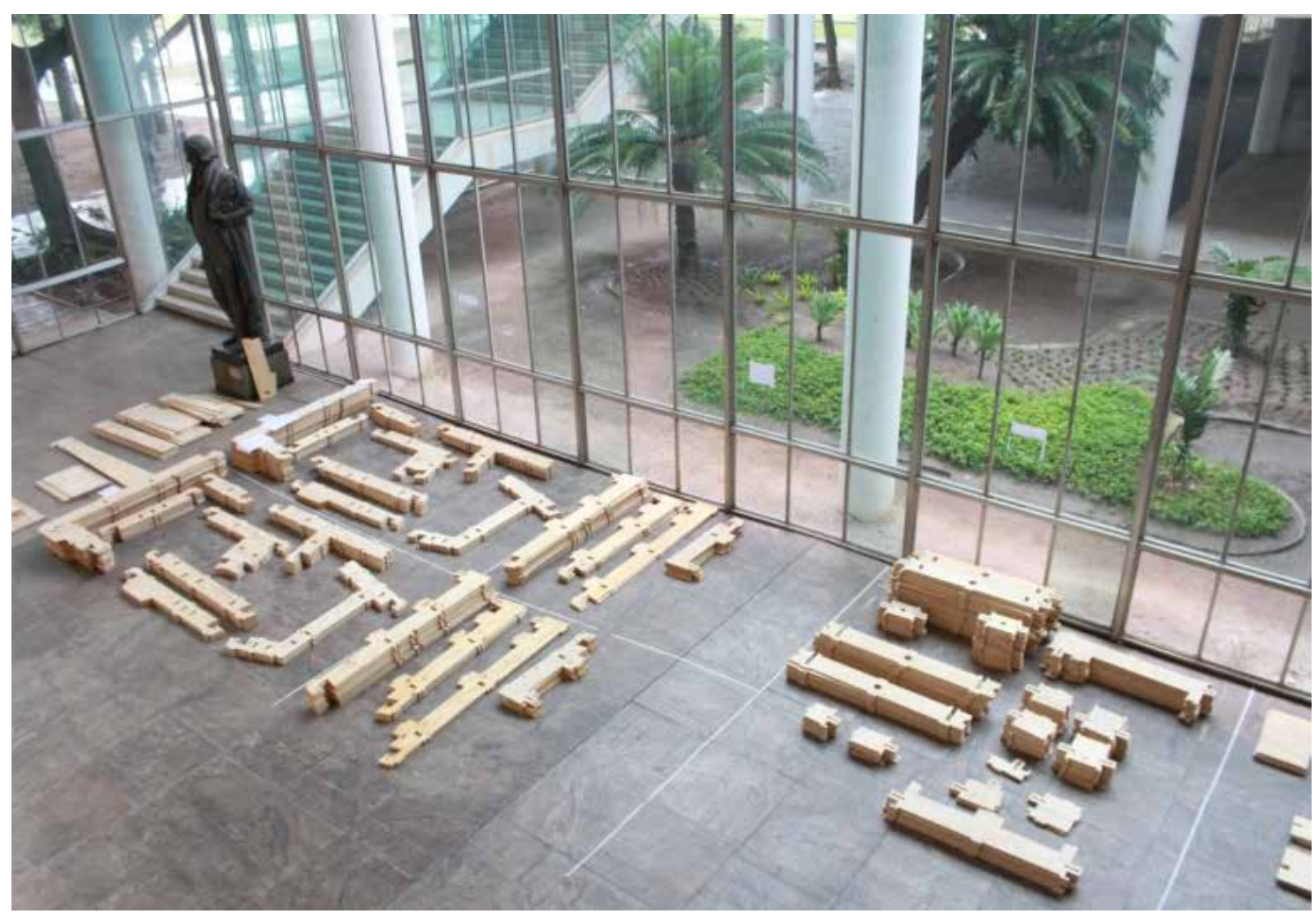




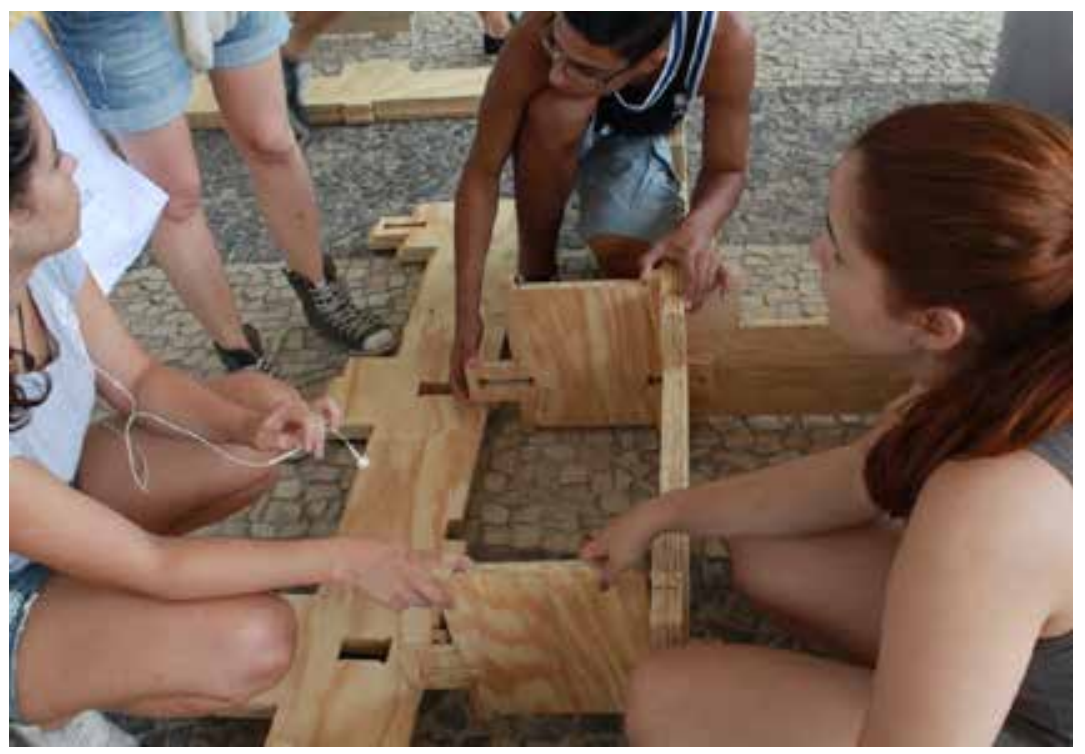

encaixava na anterior, série A e série $B$, para obter a junção ' $S$ ' invertida, e encaixava também na aba do travamento já em espera. As cunhas finais que iriam travar o sistema só poderiam ser batidas depois da estrutura de fechamento final colocada, pois esta compartilha o mesmo furo no pórtico que o travamento anterior.

A estrutura de fechamento final se encontra perpendicular aos pórticos, nas paredes leste e oeste da habitação. Por apresentar encaixes no sentido $\mathrm{y}$, foi preciso montá-la previamente para então ser acoplada à estrutura de pé apenas com encaixes no sentido $\mathrm{x}$.
Figura 11: Detalhe da montagem da estrutura de fechamento. Acervo dos autores

Figura 12: Montagem da estrutura realizada por alunos da FAU-UFRJ. Acervo dos autores.

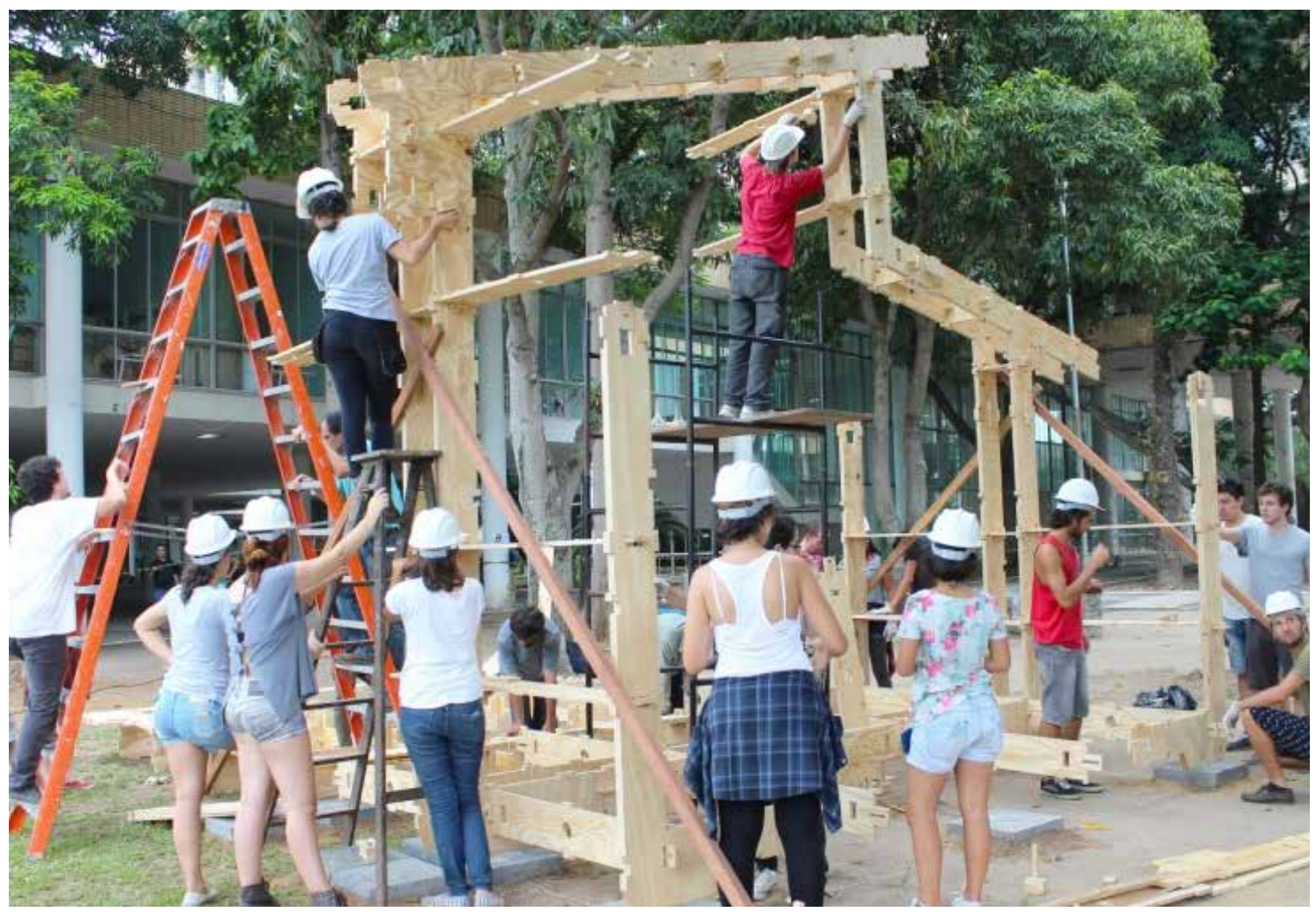


Essa lógica de montagem pôde ser percebida desde a fase de protótipos, em que se conseguia certa flexibilidade com MDF de $3 \mathrm{~mm}$ impossível de ser atingida com o compensado de $18 \mathrm{~mm}$. Para realizar tal operação, parte da equipe se distribuiu ao longo do pórtico, onde se encontravam os orifícios, enquanto a outra sustentava a estrutura e alinhava os encaixes. Todos os 16 pontos entraram simultaneamente, concluindo o esqueleto do protótipo.

Os pórticos da varanda também foram montados peça por peça, a partir da junção entre os dois pórticos (Fig 13 e 14). Em pontos estratégicos da estrutura, existem algumas variações de peças que podem ser empregadas. Se optássemos por construir apenas o pórtico maior, a terminação se daria com peça de beiral C3. A forma como optamos unir os dois pórticos utilizou uma peça J1, mas outras formas de junção entre os tipos de pórticos poderiam utilizar peças como a J2 ou J3, gerando outras tipologias.

A colocação das chapas de fechamento consistiu na etapa de maior dificuldade de montagem do protótipo (Fig 15). A estrutura montada apresentava certa deformação e maleabilidade que as chapas iriam corrigir, mas a ausência de folga entre as abas da estrutura e os orifícios das chapas dificultou muito a tarefa. Se a estrutura toda "dançava" ao ser balançada, após a colocação das chapas de fechamento percebeu-se seu enrijecimento e o papel desempenhado pelas chapas no contraventamento da estrutura. As instalações elétricas foram todas passadas anteriormente, por orifícios específicos a essa função presentes na estrutura.

Por sua localização em clima tropical úmido, com chuvas intensas, optou-se pelo recobrimento do telhado e das paredes em telha plástica. Para isso realizou-se um ripado sobre as placas de compensado para a fixação dos parafusos da telha. As aberturas receberam peças de arremate para a colocação de esquadrias padronizadas da indústria. O protótipo foi finalizado com a aplicação de outra camada de verniz e a colocação do mobiliário, produzido em mesmo material e com a mesma técnica, madeira compensada. ${ }^{12}$

\section{RESULTADOS}

O projeto usinado por estudantes de arquitetura ao longo de 2 meses e montado em mutirão em 2 semanas permitiu testar a proposta de diversas formas. Primeiro, sua funcionalidade como sistema estrutural e versatilidade ao permitir o uso de diferentes perfis, adaptando-se a diferentes climas.

${ }^{12}$ Todo o processo de montagem pode ser visto em https://vimeo.com/130312585

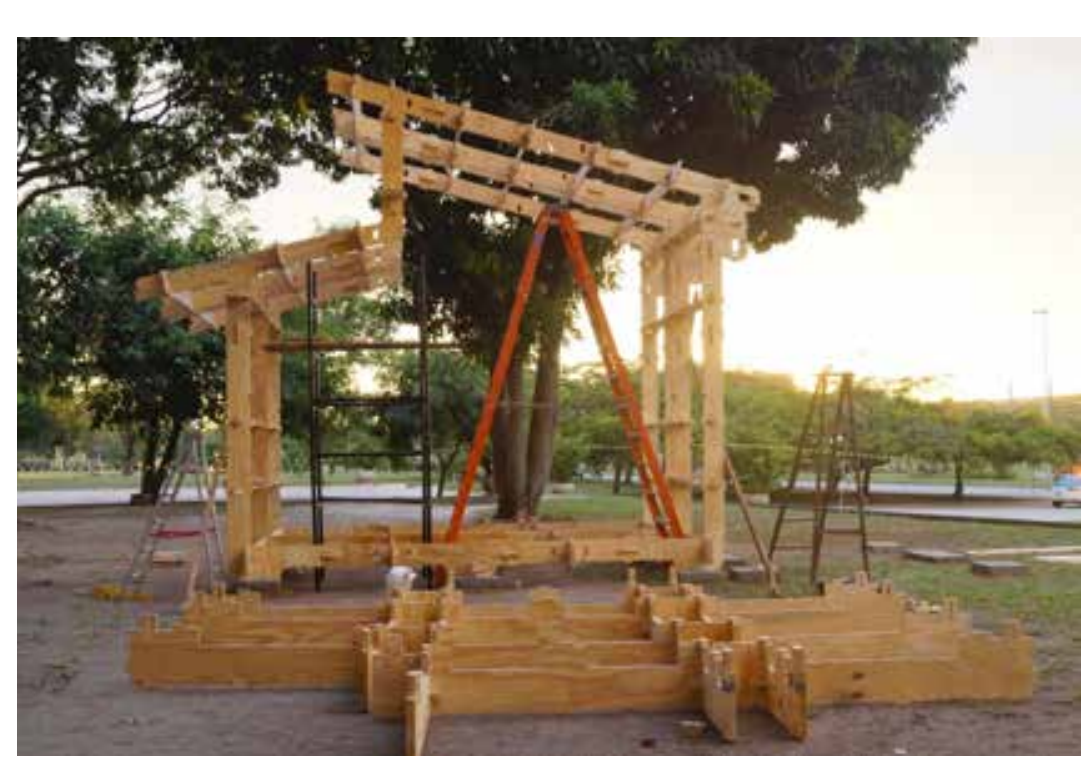

Figura 13: Estrutura de fechamento final pré-montada para encaixe no pórtico. Acervo dos autores. 


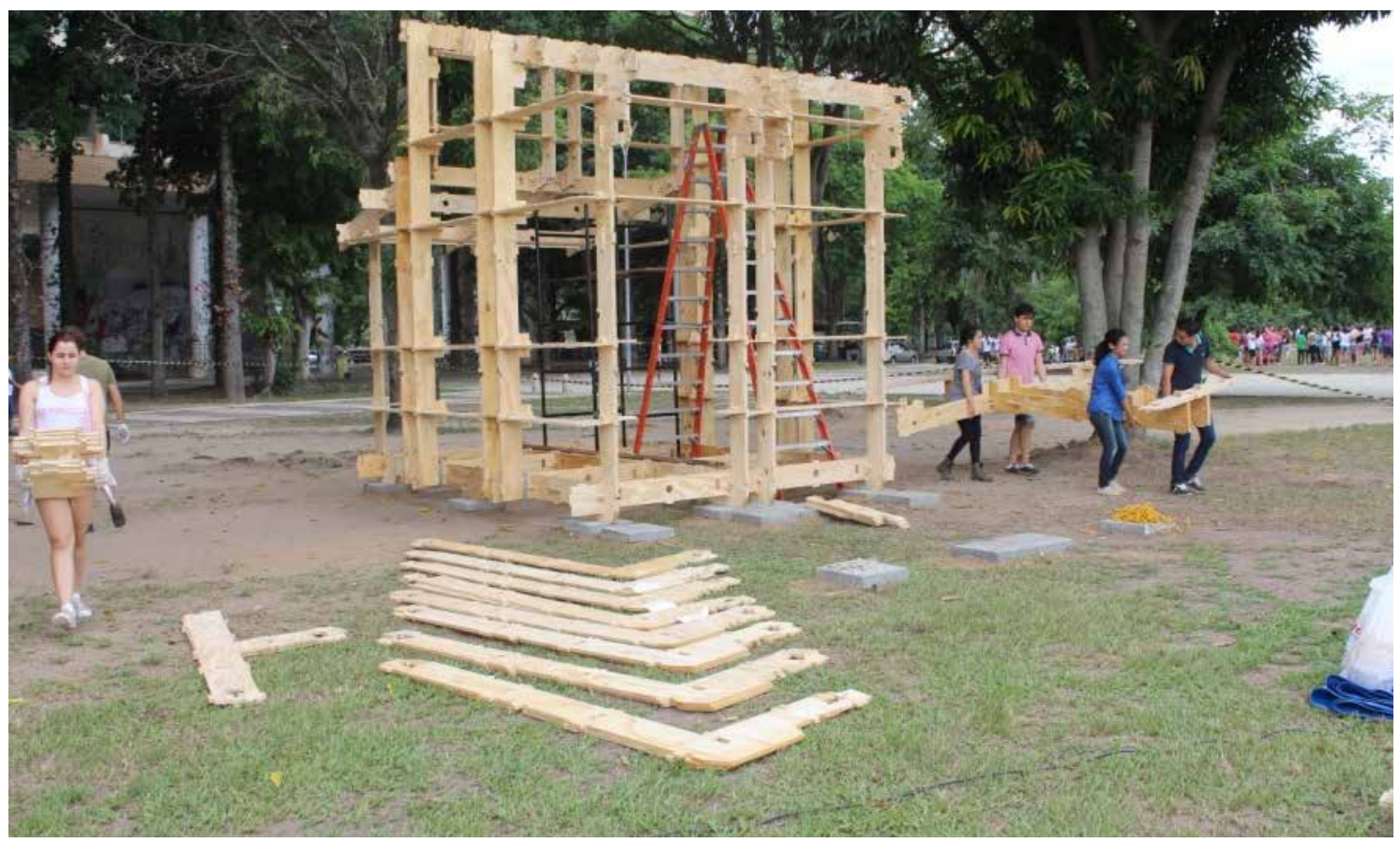

O sistema apresenta extrema firmeza quando a estrutura porticada e travada nas três direções é contraventada com o encaixe das chapas de fechamento, afinal, trata-se de um sistema que vem sendo aprimorado desde 2011 por equipes de profissionais do 00 Architecture, e parceria com Arup, renomado escritório de engenharia inglês. A cultura colaborativa permite rápido crescimento e evolução, com testes sendo realizados em todas as partes do mundo, contribuindo para um rápido avanço do conhecimento gerado pela comunidade global.

A segunda questão, a mais significativa para a proposta do projeto, foi atestar sua facilidade de aplicação para a autoconstrução. Toda a equipe envolvida no processo de fabricação e montagem não possuía conhecimento prévio do sistema ou de sua fabricação, foi um conhecimento adquirido com a prática. Em pouco tempo, a equipe de fabricação já era capaz de gerar códigos e operar a máquina router autonomamente.

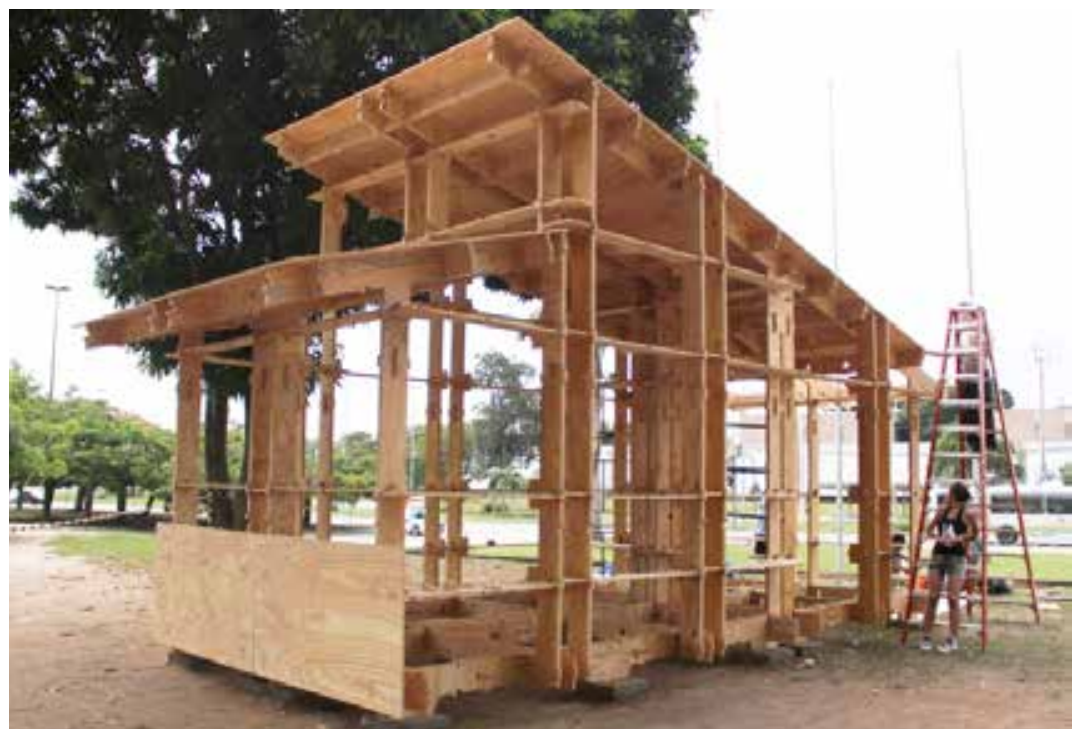

Figura 14: Estrutura de fechamento final prémontada para encaixe no pórtico. Acervo dos autores.
Figura 15: Pórticos estruturais montados e inicio da colocação dos fechamentos. Acervo dos autores. 
No mutirão de montagem, a grande maioria dos participantes entrou em contato com o sistema pela primeira vez, e em poucas horas já produziam os primeiros pórticos da habitação. O projeto se mostra intuitivo, de complexidade simples, podendo ser montado por qualquer pessoa munida de manual de instruções.

A experiência obtida revela questões a serem melhoradas assim como possibilidades de desdobramentos futuros. Apesar da racionalização do número de peças e do uso do material ter sido um princípio, as novas versões do sistema representam um avanço nesse sentido. As próximas experiências construtivas necessitam ser atualizadas para atingir uma eficiência maior da estrutura com o menor uso de material. Outra questão que envolve a qualidade do sistema construtivo é a sua vedação, pois a versão desenvolvida apresentou falhas que permitem o livre acesso de insetos ao interior do modelo.

A durabilidade da construção é outro ponto fraco, pois se tratando de madeira, são necessários tratamentos especiais que foram inviáveis ao orçamento do projeto. Para um prolongamento da durabilidade da habitação recomendamos o uso de manta de impermeabilização no telhado e paredes, sob a telha de revestimento. Na varanda, a impermeabilização através de seladora e verniz se mostrou insuficiente para um material que não apresenta resistência à água (o compensado utilizado não é naval), sendo mais bem indicada uma impermeabilização com fibra de vidro e resina, como a utilizada na impermeabilização de barcos.

Em relação à sua produção, é possível promover uma otimização no tempo de corte e de montagem, que pelas limitações existentes nos foi estendido. As oficinas promovidas tiveram o intuito didático de instrumentalizar e promover a experiência de canteiro que tanto falta aos estudantes dentro da universidade. Por isso, contaram com o tempo disponível das férias de verão e do maior número de participantes interessados, mesmo que isso implicasse em maiores dificuldades logísticas, tendo em vista a falta de experiência com o ferramental básico por parte dos alunos.

Quanto às questões de conforto ambiental, uma arquitetura bem implantada e pensada intuitivamente para o clima demonstrou ser suficiente, proporcionando um ambiente bem ventilado e fresco, mesmo nos dias mais quentes de verão. É preciso atentar para essa questão quando se trata de projetos globalizados, que não podem ser reproduzidos indiscriminadamente sem uma adaptação às condições locais. Esse conhecimento foi atribuído ao arquiteto na divisão do trabalho, mas sempre esteve presente na história das construções, podendo ser apreendido apenas pela ampliação da percepção do espaço. A arquitetura popular brasileira que reflete essa percepção às

Figura 16: Interior da casa e mobiliário produzido em router CNC. Acervo dos autores.

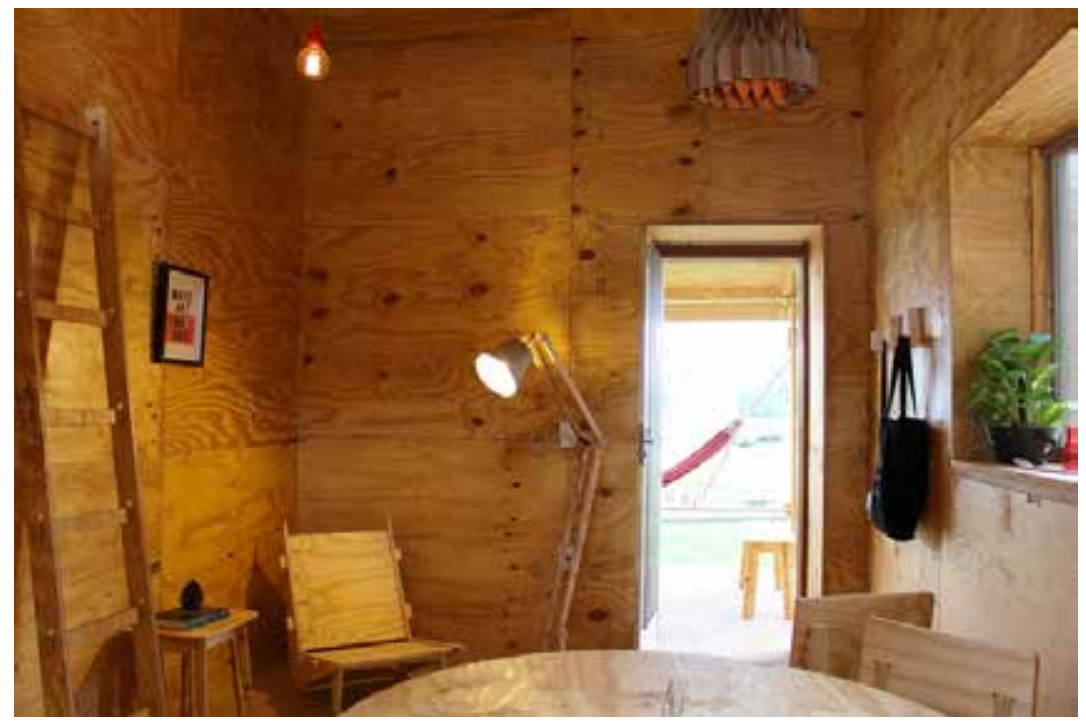


condições locais foi a fonte inspiradora para a definição dos perfis dos pórticos utilizados. A adoção de beiral e abertura zenital para a saída de ar quente e iluminação natural foram as principais adaptações do sistema ao clima tropical úmido.

\title{
PERSPECTIVAS DE FUTURO
}

A produção de arquitetura digitalmente fabricada ainda está em fase de desenvolvimento. Experiências como a de Larry Sass, no MIT ${ }^{13}$, Rodrigo Alvarado, com a Casa Generativa ${ }^{14}$, WikiHouse e ECOnnect ${ }^{15}$ abriram espaço para o surgimento de um mercado que já comercializa habitações produzidas in loco por máquinas $\mathrm{CNC}$, como o grupo Facit Homes ${ }^{16}$. Mas há muito ainda a se caminhar em busca da sua otimização, simplificação e desempenho, assim como a sua viabilidade técnica em países tidos como em 'desenvolvimento'.

A autoconstrução empírica da moradia apresenta graves problemas e esta proposta pretende dar suporte à cultura da autoconstrução dotando-a de capacidade operativa através da utilização da tecnologia de projeto e fabricação digital. Como etapa seguinte do projeto, pretendemos construir uma amostragem de habitações junto a uma população carente de moradia, envolvendo os futuros moradores no processo de fabricação e construção, e promovendo sua capacitação no uso das novas tecnologias. Para tal empreitada, nos falta justamente o ferramental de produção a ser levado in loco, a chamada Unidade Móvel de Fabricação, do Centro Avançado de Fabricação e Experimentação Digital - CAFE, uma extensão do LAMO3D. O CAFE está em processo de aquisição de duas unidades robóticas de 6 eixos, mas ainda sem perspectiva para a aquisição da router de 3 eixos.

O objetivo do projeto em sua continuação é avaliar a funcionalidade da casa de fonte aberta abrasileirada através de seu uso e apropriação pelos moradores, assim como experimentar sua produção dentro de um sistema autogestionário e democrático, implementada como tecnologia social.

\begin{abstract}
"Assumir o projeto open source como uma tecnologia social é um passo fundamental para a sua inserção em uma economia solidária, uma economia que considera o ser humano como sujeito e finalidade das atividades econômicas, que prioriza o conhecimento e a autonomia da classe trabalhadora, onde outros modos de produção podem florescer. (...) É nesse meio que a arquitetura open source encontra força para exercer sua função social, entre associação de moradores e produtores de habitação, cooperativas empreendedoras da fabricação digital que contem com a ajuda de instituições de incentivo à pesquisa para compra do maquinário, e coletivos independentes que promovam a emancipação humana." (Passaro e Rohde, 2014).
\end{abstract}

A popularização de um novo sistema de fabricação para produção autônoma da habitação é de futuro incerto, mas é importante ressaltar o potencial do conhecimento de fonte aberta na produção de uma sociedade mais justa. É através da rede de conhecimento global compartilhado que as tecnologias que vêm revolucionando os modos de produção podem também alterar os meios de produção. $\mathrm{O}$ acesso massivo à tecnologia, que se limita atualmente às ferramentas de consumo alienadoras, chegará às ferramentas de produção que têm potencial para alterar toda a ordem socioeconômica vigente.

\footnotetext{
${ }^{13}$ http://ddf.mit.edu/milestone/03

${ }^{14}$ http://casagenerativa.blogspot.com.br

${ }^{15}$ http://www.eco-nnect.eu

${ }^{16}$ http://facit-homes.com
} 
A arquitetura de fonte aberta tem potencial para alcançar toda uma população excluída do sistema, que no Brasil, fica inteiramente responsável pela autoconstrução de sua moradia. O país foi e continua sendo autoconstruído, e o papel dos arquitetos por aqui é conectar essa população com projetos colaborativos de rápida produção, provendo qualidade técnica e ambiental à autoconstrução. Na Inglaterra, o grupo WikiHouse identifica o potencial das novas tecnologias de fabricação como alternativa à crise do mercado imobiliário que o país enfrenta, com a queda da produção de habitações estandardizadas pelo Estado e pelo mercado. No video Homes by People, Alastair Parvin aponta um terceiro setor como o responsável por uma mudança no panorama, a sociedade. Defende a produção independente e personalizada de habitações, promovida por uma associação de moradores através da contratação direta dos desenvolvedores do projeto, tirando partido da customização em massa da produção permitida pelas novas tecnologias de fabricação.

\title{
CONCLUSÕES
}

As técnicas, e sua evolução, estão diretamente relacionadas com os modos de produção, as relações de produção e os espaços produzidos. As tecnologias de fabricação digital estão alterando os modos de produção, e na era da informação, o compartilhamento do conhecimento livre abre caminho para uma alteração das relações de produção mais profunda. A cultura livre e o conhecimento aberto são instrumentos de empoderamento da população, permitem a atuação de indivíduos de forma colaborativa em benefício público, assumindo os avanços do conhecimento humano como um bem construído pela humanidade ao longo de sua evolução, e por isso de domínio público.

\begin{abstract}
"Na hora atual, e para a maior parte da humanidade, a globalização é sobretudo fábula e perversidade: fábula, porque os gigantescos recursos de uma informação globalizada são utilizados mais para confundir do que para esclarecer: a transferência não passa de uma promessa. (...) Perversidade, porque as formas concretas dominantes de realização da globalidade são o vício, a violência, o empobrecimento material, cultural e moral, possibilitados pelo discurso e pela prática da competitividade em todos os níveis. O que se tem buscado não é a união, mas antes a unificação.” (Santos,1994, p. 27).
\end{abstract}

Milton Santos não viveu para ver surgir o movimento pelo conhecimento aberto, que tem o potencial de transformar a economia capitalista vigente em uma economia de fonte aberta, menos monopolizada e hegemônica, que substitui a lógica da competitividade pela colaboratividade.

As discussões dentro dessa esfera ainda são escassas, com poucos estudos sobre seu impacto e aplicações. Estão limitadas aos grupos que primeiro desenvolveram a ideia e a seguem defendendo, como a Organização Creative Commons , criadora de licenças de uso com alguns direitos reservados, personalizáveis pelo criador que compartilha sua criação. O livre acesso à informação e ao conhecimento tem o potencial de moldar uma nova globalização, uma globalização de inclusão, que valorize o homem acima do dinheiro. Uma mudança de regime ou reorganização de um sistema começa com mudanças na percepção, análise e respostas ao mundo que nos cerca (Karakiewick, 2015), e a academia tem papel fundamental nesse processo. É dentro das instituições de ensino e pesquisa, principalmente as públicas, que a liberação da informação deve ser assumida como ferramenta de transformação, evolução e superação da condição atual, fundamentando as bases de atuação do futuro, no qual, a questão do livre acesso à informação será assunto de bar, discutido em toda esquina, fundamental ao exercício da democracia. 
O projeto de arquitetura de fonte aberta apresentado defende a transparência de processos e produtos, dando acesso à informação e ao seu entendimento, apropriação e transfiguração. Sua aplicação como tecnologia social, transferindo o conhecimento acadêmico à sociedade, e a popularização das tecnologias de fabricação, levantam algumas questões que permanecem abertas. Como a tecnologia aberta será absorvida pela cultura popular? Como a população irá lidar com as tecnologias disponíveis? Como irá se apropriar e as transformar? Quais demandas irão primeiro se utilizar das tecnologias de fabricação? Que lógicas de produção serão aplicadas? Que tomada de consciência as novas práticas irão despertar?

Mercados estão dando lugar a redes, a posse está perdendo força através do acesso e a colaboração vem reformulando as formas de produção. Essas mudanças são um ensaio para uma transição a um novo sistema econômico, aberto e colaborativo. É o início de uma nova cognoscibilidade no planeta, onde ideias, mecanismos, programas, projetos e produtos farão parte do nosso grande banco de dados para produção, explorando o potencial do acesso universal ao conhecimento humano.

\section{AGRADECIMENTOS}

A Casa Revista foi construída com o apoio da FAPERJ e CNPQ, em parceria com a Foco Design, que disponibilizou a máquina e o espaço para a realização dos cortes, e com a Sudati Sudply que nos forneceu o material. Agradecemos a toda equipe LAMO3D e a todos os estudantes que participaram da fabricação e construção da casa, assim como todos os professores e funcionários da UFRJ que contribuíram com o projeto.

\section{REFERÊNCIAS}

CHAUI, Marilena.Conformismo e resistência. Belo Horizonte: Autêntica Editora, 2014.

GRAMAZIO, Fabio; KOHLER Matthias. The Robotic Touch: How robots change architecture. Zurich: Park Books, 2014.

KARAKIEWICZ, Justyna; BURRY, Mark; KVAN, Thomas. The next city and complex adaptive Systems. 16th International Caad Futures Conference. São Paulo: Springer Book, 2015.

NAN, Cristina. A New Machinecraft: A critical evolution of Architectural Robots, 16th International Caad Futures Conference. São Paulo: Springer Book,
2015.

RIBEIRO, Darcy. O Brasil como problema. São Paulo: Editora Siciliano, 1990.

PASSARO, Andrés; ROHDE, Clarice. Casa Revista. Anais do Seminário Habitar, Belo Horizonte, 2014.

SANTOS, Milton. Técnica, Espaço, Tempo: Globalização e meio técnico-científico informacional. São Paulo: Hucitec, 1994.

SANTOS, Milton. Por uma outra globalização: do pensamento único à consciência universal. Rio de Janeiro: Record, 2000.

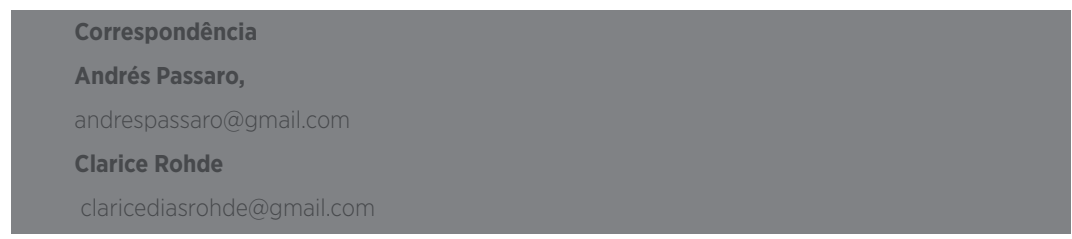

